\title{
Biolohy og Euseius scutalis (Acari: Phytoseiidae) on Tetranychus urticae and Panonychus ulmi (Acari: Tetranychidae) at Different Temperatures
}

\author{
M. R. Abbassy ; H. H. Hendy ${ }^{* *}$; M. H. Mowafi ${ }^{\star}$ and M. A. Nawar ${ }^{* \star}$ \\ "Zoology and Nematology Department, Faculty of Agriculture. Al-Azhar University, Cairo. Egypt. \\ "Plant Protection Department, Nematology Unit, Desert Research Center, Cairo, Egypt.
}

\begin{abstract}
This study was conducted to determine the effect of different temperatures and prey type on the biology of Euseius scutalis Athias-Henriot (Acari: Phytoseiidae) fed on Tetranychus urticae Koch and Panonychus ulmi (Koch) (Acari: Tetranychidae) at 20,25 and $30^{\circ} \mathrm{C}$. The incubation period of E. scutalis was shortened with increasing temperature. The mean duration of immature stages was 10.3, 12.7; 7.0, 9.8 and 4.1, 5.7 days when the mite females fed on $T$. urticae and P. ulmi at 20,25 and $30^{\circ} \mathrm{C}$, respectively. The life cycle duration was $14.0,15.5 ; 9.1,12.4$ and $5.6,7.9$ days when the females were fed on the aforementioned conditions, respectively. Average female longevity on T. urticae and P. ulmi was $27.7 \& 31.9$ days at $20^{\circ} \mathrm{C}$, followed by $22.4 \& 25.7$ days at $25^{\circ} \mathrm{C}$ and $15.7 \& 20.4$ days at $30^{\circ} \mathrm{C}$, respectively. The maximum average fecundity (44.2 eggs/female) was observed at $25^{\circ} \mathrm{C}$ when females fed on T. urticae compared with 35.6 eggs/feinale on $P$. ulmi. Obtained relative values for males were generally less than those of females. Effect of temperature on obtained biological values expressed as rates (1/duration) between main aspects and tested temperatures was significant. Obtained $R^{2}$ values ranged between 0.90 and 0.655 with $P<0.001$. It was concluded that $T$. urticae was preferred prey than $P$. ulmi and $30^{\circ} \mathrm{C}$ was the best for individual developmental rate while $25^{\circ} \mathrm{C}$ was the best for most fecundity regardless tested prey.
\end{abstract}

Key Words: Biology, Euseius scutalis, Phytoseiidae, Temperature, Tetranychidae.

\section{INTRODUCTION}

Members of the family Phytoseiidae have received considerably worldwide attention because of their potential as natural enemies of phytophagous mites. Euseius is a cosmopolitan genus which contains many species known to be facultative feeders on mite and insects with higher productivity on pollen (Mc Murty and Croft 1997).

Biology of some members of the genus Euseius was reported by authors on various prey types and different temperatures (Abou-Setta \& Childers, 1987; Furtado \& Moraes, 1998; Abd El-Halim et al., 2000; Raza et al., 2005; Kasap, 2008 and AlShammery 2010). The development and reproduction of the predatory mite Euseius scutalis Athias-Henriot (Acari: Phytoseiidae) when reared on pollen of $M$. crocea was reported (Bounfour and McMurty 1987).

The developmental time, survival and fecundity of Euseius septicus Chaudhari were determined at different temperatures $\left(20,25\right.$ and $\left.30^{\circ} \mathrm{C}\right)$ and $60-70 \%$ R.H. fed on the two spotted spider mite (Raza et al., 2005). Larval, nymphal, preoviposition and postoviposition period decreased as temperature increased.

The differences in biological aspects of Euseius finlanandicus when fed on Tetranychus urticae Koch (Acari: Tetranychidae) together with birch pollen at $16,20,25$ and $30^{\circ} \mathrm{C}$ at $65 \%$ R.H. and $16: 8$ photoperiod was reported (Kasap, 2008).
As a step towards evaluation of E. scutalis in bio-control, the effect of different temperatures on the biology of this species feding on the two spotted spider mite T. urticae and the European red mites, Panonychus ulmi (Koch) (Acari: Tetranychidae) under the laboratory conditions, was studied.

\section{MATERIALS AND METHODS}

The experiment was carried out under the laboratory conditions. E. scutalis culture was maintained using all the stages of $T$. urticae as prey. The effect of different temperatures on the viology of E. scutalis was determined by using water soaked cotton arena. This arena consisted of water soaked cotton ring of $1 \mathrm{~cm}$ diameter that was placed over plastic sheet $(7 \times 7 \mathrm{~cm})$ with a piece of blotting paper and fresh leaf placed in between the cotton ring and plastic sheet. Blotting paper and cotton ring kept moist through capillary action of water via piece of cotton that was dipped in water source. Cotton ring was used as a barrier to prevent the escape of mites from the arena. Moist blotting paper kept the leaf fresh for 4-5 days. The old leaf in arena was replaced with fresh leaf after $4-5$ days.

The spider mites, T. urticae and P. ulmi were transferred from the laboratory cultures to the Petri dishes by using camel hair brush and then E. scutalis females were transferred to each petri-dish for egg laying and removed after completed oviposition. The Petri-dishes were kept separately in growth 
chambers set at three temperatures (i.e. 20, 25 and $30^{\circ} \mathrm{C}$ ). Each treatment consisted of five Petri dishes, containing 5 discs each. The characters observed included incubation period, duration of protonymph, deutonymph, preovipostion, oviposition and postoviposition periods and longevity at each temperature.

The statistical analysis (ANOVA and Regression) of the obtained results were performed using SAS program (SAS Institute, 1988).

\section{RESULTS AND DISCUSSION}

The present experiment was conducted to determine the effect of different temperatures and prey type on the duration of various life stages, adult longevity and fecundity of $E$. scutalis fed on $T$. urticae and $P$. ulmi. Obtained results and their significances are presented in Tables (land 2).

\section{Incubation period:}

Incubation period of E. scutalis averaged $3.7 \&$ 2.8 days at $20^{\circ} \mathrm{C} ; 2.1 \& 2.6$ days at $25^{\circ} \mathrm{C}$; and $1.5 \&$ 2.2 days at $30^{\circ} \mathrm{C}$ when reared on T. urticae and $P$. ulmi, respectively; this period decreased with temperature increase.

\section{Larval stage:}

At $20^{\circ} \mathrm{C}$, E. scutalis females larval period was 2.3 and 2.9 days when fed on T. urticae and P. ulmi, respectively (Table 1 ). It was 1.9 and 2.3 days when males larval mite fed on these diets at $20^{\circ} \mathrm{C}$, respectively. However, when the temperature increased to $25^{\circ} \mathrm{C}$, the larval period was 1.5 and 2.5 days for females and 1.4 and 2.0 days for males, respectively. At 30 , females larval period was 0.8 and 1.4 days, respectively.

\section{Protonymphal stage:}

The mean protonymphal period of E. scutalis remale and male was $3.1 \& 2.5$ and $4.5 \& 3.8$ days when fed on $T$. urticae and $P$. ulmi, at $20^{\circ} \mathrm{C}$, respectively. However, when the temperature increased to $25^{\circ} \mathrm{C}$, the protonymphal stage period of this mite lasted $2.4 \& 3.2$ days for females and 2.1 \& 2.9 days for males, respectively. On the other hand, at $30^{\circ} \mathrm{C}$, the protonymph of E. scutalis lasted $1.1 \&$ 2.1 for females and $0.7 \& 1.7$ days for males when fed on the same prey, respectively (Table 1).

\section{Deutonymphal stage:}

The mean deutonymphal period of E. scutalis was 4.9 and 5.3 days for female individuals when reared on $T$. urticae and $P$. ulmi at $20^{\circ} \mathrm{C}$, respectively. This period was $3.8 \& 4.5$ days for males. This stage lasted $3.1 \& 4.1 ; 2.9 \& 3.4$ days for females and males at $25^{\circ} \mathrm{C}$, respectively. On the other aand, the deutonymphal period of $E$. scutalis as observed at $30^{\circ} \mathrm{C}$ lasted $2.2,3.0 ; 1.5$ and 2.6 days, respectively. (Table 1).

\section{Life cycle:}

The mean duration of life cycle for individuals was $14.0,15.5$ and $11.5,13.4$ days when the E. scutalis females and males fed on T. urticae and $P$. ulmi at $20^{\circ} \mathrm{C}$, respectively. However, this period decreased at $30^{\circ} \mathrm{C}$ averaging 5.6, 7.9 and $4.1,7.4$ days, respectively. (Table 1).

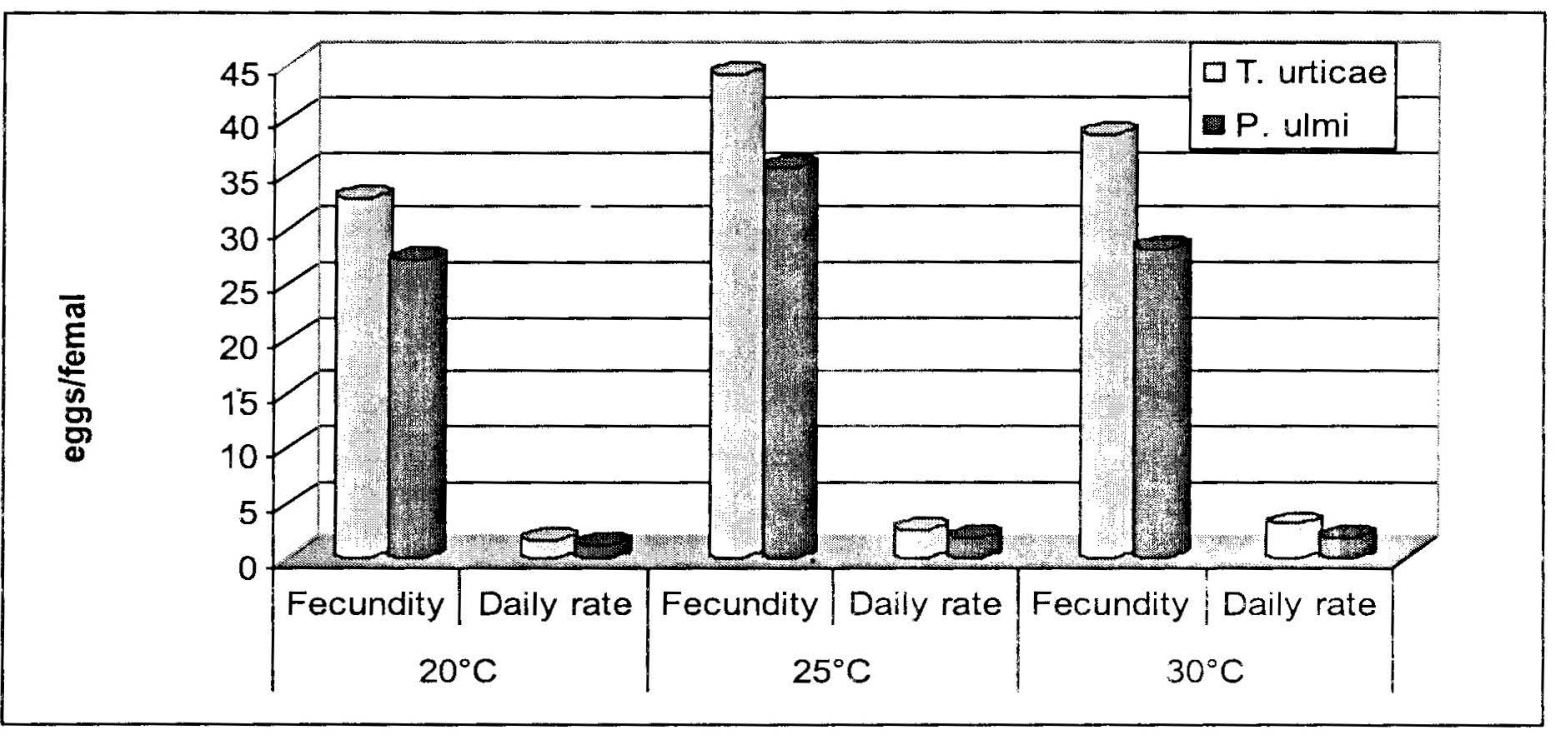

Fig. (1): Effect of prey type on E. scutalis female fecundity and daily rate when fed on $T$. urticae and P. ulmi. 
Table (1): Duration (mean+SD) of different stages of E. scutalis when fed on $T$. urticae and $P$. ulmi.

\begin{tabular}{|c|c|c|c|c|c|c|c|}
\hline \multirow{2}{*}{ Predator stage } & \multirow{2}{*}{ Sex } & \multicolumn{2}{|c|}{$20^{\circ} \mathrm{C}$} & \multicolumn{2}{|c|}{$25^{\circ} \mathrm{C}$} & \multicolumn{2}{|c|}{$30^{\circ} \mathrm{C}$} \\
\hline & & T. urtica & P. ulmi & T. urticae & P. ulmi & T. urticae & P. ulmi \\
\hline \multirow{2}{*}{ Egg } & $q$ & $3.7 \pm 0.54$ & $2.8 \pm 0.54$ & $2.1 \pm 0.54$ & $2.6 \pm 0.54$ & $1.5 \pm 0.41$ & $2.2 \pm 0.41$ \\
\hline & 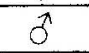 & $3.3 \pm 0.74$ & $2.8 \pm 0.74$ & $1.9 \pm 0.50$ & $2.3 \pm 0.50$ & $1.3 \pm 0.44$ & $1.9 \pm 0.45$ \\
\hline \multirow{2}{*}{ Larva } & 9 & $2.3 \pm 0.57$ & $2.9 \pm 0.27$ & $1.5 \pm 0.22$ & $2.5 \pm 0.41$ & $0.8 \pm 0.27$ & $1.4 \pm 0.27$ \\
\hline & $\delta^{2}$ & $1.9 \pm 0.41$ & $2.3 \pm 0.41$ & $1.4 \pm 0.27$ & $2.0 \pm 0.27$ & $0.6 \pm 0.22$ & $1.2 \pm 0.27$ \\
\hline \multirow{2}{*}{ Protonymph } & 웅 & $3.1 \pm 0.41$ & $4.5 \pm 0.42$ & $2.4 \pm 0.27$ & $3.2 \pm 0.50$ & $1.1 \pm 0.44$ & $2.1 \pm 0.27$ \\
\hline & $0^{\pi}$ & $2.5 \pm 0.41$ & $3.8 \pm 1.11$ & $2.1 \pm 0.22$ & $2.9 \pm 0.44$ & $0.7 \pm 0.22$ & $1.7 \pm 0.35$ \\
\hline \multirow{2}{*}{ Deutonymph } & 오 & $4.9 \pm 0.22$ & $5.3 \pm 0.27$ & $3.1 \pm 0.27$ & $4.1 \pm 0.75$ & $2.2 \pm 0.54$ & $3.0 \pm 0.50$ \\
\hline & $\hat{g}$ & $3.8 \pm 0.41$ & $4.5 \pm 0.65$ & $2.9 \pm 0.27$ & $3.4 \pm 0.41$ & $1.5 \pm 0.41$ & $2.6 \pm 0.44$ \\
\hline \multirow{2}{*}{ Total immatures } & 9 & $10.3 \pm 1.03$ & $12.7 \pm 0.41$ & $7.0 \pm 0.22$ & $9.8 \pm 0.67$ & $4.1 \pm 0.83$ & $5.7 \pm 0.96$ \\
\hline & $\frac{1}{c}$ & $8.2 \pm 0.75$ & $10.6 \pm 1.64$ & $5.5 \pm 0.44$ & $8.3 \pm 0.83$ & $2.8 \pm 0.65$ & $5.5 \pm 0.86$ \\
\hline \multirow{2}{*}{ Life cycle } & 우 & $14.0 \pm 1.29$ & $15.5 \pm 0.70$ & $9.1 \pm 0.57$ & $12.4 \pm 1.03$ & $5.6 \pm 1.15$ & $7.9 \pm 1.35$ \\
\hline & 8 & $11.5 \pm 1.39$ & $13.4 \pm 1.98$ & $7.4 \pm 0.93$ & $10.4 \pm 1.25$ & $4.1 \pm 0.65$ & $7.4 \pm 1.30$ \\
\hline \multirow{2}{*}{ Longevity } & 9 & $27.7 \pm 1.47$ & $31.9 \pm 1.18$ & $22.4 \pm 2.10$ & $25.7 \pm 1.67$ & $15.7 \pm 2.59$ & $20.4 \pm 3.71$ \\
\hline & 8 & $24.0 \pm 1.14$ & $27.4 \pm 1.87$ & $19.2 \pm 1.30$ & $22.0 \pm 1.67$ & $12.8 \pm 1.94$ & $16.0 \pm 0.89$ \\
\hline \multirow{2}{*}{ Life span } & 9 & $41.7 \pm 1.64$ & $47.4 \pm 0.62$ & $31.5 \pm 1.39$ & $38.1 \pm 1.67$ & $21.3 \pm 1.72$ & $28.3 \pm 1.34$ \\
\hline & 8 & $35.5 \pm 1.07$ & $40.8 \pm 1.91$ & $26.5 \pm 1.10$ & $30.3 \pm 1.71$ & $18.9 \pm 1.98$ & $22.9 \pm 2.07$ \\
\hline Fre-oviposition & $q$ & $3.1 \pm 0.75$ & $3.2 \pm 0.35$ & $2.0 \pm 0.44$ & $2.60 \pm 0.22$ & $1.3 \pm 0.44$ & $2.18 \pm 1.25$ \\
\hline viposition & 早 & $20.4 \pm 1.67$ & $23.4 \pm 2.58$ & $17.6 \pm 1.92$ & $19.30 \pm 0.30$ & $12.6 \pm 2.40$ & $15.6 \pm 3.11$ \\
\hline Post-oviposition & 우 & $4.20 \pm 1.30$ & $5.30 \pm 0.89$ & $2.8 \pm 0.83$ & $3.80 \pm 0.89$ & $1.8 \pm 0.83$ & $2.7 \pm 0.97$ \\
\hline
\end{tabular}

Table (2): Significance of different duration means for the different stages of E. scutalis when fed on $T$. urticae and $P$. ulmi.

\begin{tabular}{|c|c|c|c|c|c|}
\hline Stage & Prey type & Mean & & $F$ value & $\mathrm{P}$ \\
\hline \multirow{2}{*}{ Egg } & T. urticae & 2.3 & a & \multirow{2}{*}{0.26} & \multirow{2}{*}{0.612} \\
\hline & P. ulmi & 2.4 & $\mathrm{a}$ & & \\
\hline \multirow{2}{*}{ Larva } & T. urticae & 1.4 & $a$ & \multirow{2}{*}{10.45} & \multirow{2}{*}{0.0021} \\
\hline & P. ulmi & 2.0 & b & & \\
\hline \multirow{2}{*}{ Protonymph } & T. urticae & 1.9 & $\mathrm{a}$ & \multirow{2}{*}{23.07} & \multirow{2}{*}{0.0001} \\
\hline & P. ulmi & 3.0 & $\mathrm{~b}$ & & \\
\hline \multirow{2}{*}{ Deutonymph } & T. urticae & 3.1 & $a$ & \multirow{2}{*}{10.46} & \multirow{2}{*}{0.0021} \\
\hline & P. ulmi & 3.8 & $\mathrm{~b}$ & & \\
\hline \multirow{2}{*}{ Total immatures } & T. urticae & 6.3 & $\mathrm{a}$ & \multirow{2}{*}{37.45} & \multirow{2}{*}{0.0001} \\
\hline & P. ulmi & 8.7 & $\mathrm{~b}$ & & \\
\hline \multirow{2}{*}{ Pre-oviposition } & T. urticae & 2.1 & $\mathrm{a}$ & \multirow{2}{*}{1.97} & \multirow{2}{*}{0.1726} \\
\hline & P. ulmi & 2.7 & $\mathrm{a}$ & & \\
\hline \multirow{2}{*}{ Oviposition } & T. urticae & 16.9 & $\mathrm{a}$ & \multirow{2}{*}{6.36} & \multirow{2}{*}{0.0181} \\
\hline & P. ulmi & 19.4 & $\mathrm{~b}$ & & \\
\hline \multirow{2}{*}{ Post-oviposition } & T. urtica & 2.9 & $\mathrm{a}$ & \multirow{2}{*}{7.22} & \multirow{2}{*}{0.0032} \\
\hline & P. ulmi & 3.9 & $\mathrm{~b}$ & & \\
\hline \multirow{2}{*}{ Total egg } & T. urtica & 38.5 & $\mathrm{~b}$ & \multirow{2}{*}{14.39} & \multirow{2}{*}{0.0008} \\
\hline & P. ulmi & 30.3 & $\mathrm{a}$ & & \\
\hline \multirow{2}{*}{ Longevity } & T. urtica & 20.3 & $\mathrm{a}$ & \multirow{2}{*}{27.58} & \multirow{2}{*}{0.0001} \\
\hline & P. ulmi & 23.9 & $b$ & & \\
\hline \multirow{2}{*}{ Life span } & T. urtica & 29.3 & $\mathrm{a}$ & \multirow{2}{*}{29.34} & \multirow{2}{*}{0.0001} \\
\hline & P. ulmi & 34.6 & b & & \\
\hline
\end{tabular}


Table (3): Regression values for relation between selected biological aspects rate and temperature using different types of prey

\begin{tabular}{|c|c|c|c|c|c|c|}
\hline Prey type & Stage & Sex & $\mathrm{a}$ & $\mathrm{b}$ & $\mathrm{P}$ & $\mathrm{R}^{2}$ \\
\hline \multirow{8}{*}{ T. urticae } & \multirow{2}{*}{$\begin{array}{c}\text { Total } \\
\text { immature }\end{array}$} & 9 & -0.6096 & 0.0068 & 0.0001 & 0.8841 \\
\hline & & $\frac{1}{d}$ & -0.0990 & 0.0090 & 0.0003 & 0.6550 \\
\hline & \multirow{2}{*}{ Life cycle } & q & -0.0256 & 0.0044 & 0.0001 & 0.8616 \\
\hline & & $\frac{t}{0^{n}}$ & -0.0050 & 0.0063 & 0.0001 & 0.7500 \\
\hline & \multirow{2}{*}{ Longevity } & 9 & -0.0440 & 0.0100 & 0.0001 & 0.9026 \\
\hline & & $\sigma^{\lambda}$ & -0.0190 & 0.0027 & 0.0001 & 0.7790 \\
\hline & \multirow{2}{*}{ Life span } & Q & -0.0090 & 0.0014 & 0.0001 & 0.7620 \\
\hline & & $\frac{\pi}{d}$ & -0.0168 & 0.0020 & 0.0001 & 0.7559 \\
\hline \multirow{8}{*}{ P. ulmi } & \multirow{2}{*}{$\begin{array}{c}\text { Total } \\
\text { immature }\end{array}$} & 웅 & -0.1927 & 0.0144 & 0.0001 & 0.7117 \\
\hline & & $\delta$ & -0.3810 & 0.0240 & 0.0001 & 0.7087 \\
\hline & \multirow{2}{*}{ Life cycle } & q & -0.1150 & 0.0097 & 0.0001 & 0.6980 \\
\hline & & $\sigma^{\lambda}$ & -0.2479 & 0.0160 & 0.0001 & 0.7840 \\
\hline & \multirow{2}{*}{ Longevity } & 9 & -0.0200 & 0.0027 & 0.0001 & 0.7750 \\
\hline & & $\frac{t}{d}$ & -0.0350 & 0.0037 & 0.0001 & 0.7548 \\
\hline & \multirow{2}{*}{ Life span } & 오 & -0.0197 & 0.0021 & 0.0001 & 0.8230 \\
\hline & & $\delta$ & -0.0296 & 0.0028 & 0.0001 & 0.7051 \\
\hline
\end{tabular}

\section{Adult longevity:}

Mean female longevity was $27.7 \& 31.9$ days at $20^{\circ} \mathrm{C} ; 22.4 \& 25.7$ days at $25^{\circ} \mathrm{C}$ and $15.7 \& 20.4$ days at $30^{\circ} \mathrm{C}$, when fed on T. urticae, and $P$. ulmi, respectively. The differences were significant $(\mathrm{P}<0.05)$. On the other hand the male longevity was $24.0 \& 27.4$ at $20^{\circ} \mathrm{C}, 19.2 \& 22.0$ days at $20^{\circ} \mathrm{C}$, but at $30^{\circ} \mathrm{C}$, it was 12.8 and 16.0 days, respectively. (Table 1).

Immature stages were affected significantly by both studied factors (i.e. prey type and temperature). The general trend was that obtained durations were significantly longer on $P$. ulmi than $T$. urticae. This applied to both females and males. There results indicated that $T$. urticae was the preferred prey compared with $P$. ulmi. Obtained relative values for males were generally less than females.

\section{Female specific results:}

Pre-ovipostion, oviposition and post-oviposition periods were longer on $P$. ulmi than $T$. urticae regardless tested temperature. Total fecundity and daily rate were significantly higher on $T$. urticae than P. ulmi (Table 2). Fecundity and daily oviposition rates are illustrated (Fig1). The mean of deposited eggs and daily rate were $32.8,1.59$ and $27.2,1.16 \mathrm{eggs} / \mathrm{female}$ at $20^{\circ} \mathrm{C}$ on $T$. urticae and $P$. ulmi, respectively. These values were $44.2,2.54$ and $35.6,1.84 \mathrm{eggs} /$ female at $25^{\circ} \mathrm{C}$ and $38.6,3.1$ and $28.2,1.8 \mathrm{eggs} / \mathrm{female}$ at $30^{\circ} \mathrm{C}$, respectively.

\section{Effect of temperature:}

This relation was expressed between main aspects durations as rate (1/duration) and tested temperatures. The main aspects considered were total immatures, life cycle, and life span. Results revealed strong significant regression relations. $R^{2}$ values ranged between 0.6550 and 0.9026 with $\mathrm{P}<0.001$ (Table 3).

These results conformed the relation between main aspects durations and temperature. Generally it could be concluded that $30^{\circ} \mathrm{C}$ was the best for individual developmental rate, while $25^{\circ} \mathrm{C}$ was the best for population increase where most fecundity occurred.

The present study clearly indicated the effect of different temperatures and prey type on the developmental time of different stages of $E$. scutalis. The results can be compared with Kasap and Sekeroglu (2004) who reported that total developmental times of $E$. scutalis were 6.7, 4.9 and 4.2 days at 20,25 and $30^{\circ} \mathrm{C}$, respectively using a diet of all stages of citrus red mite, Panonychus citri (McGregor). In general, pre-oviposition and postoviposition periods of $E$. scutalis were shortened as temperature increased, but the oviposition period was longer at $25^{\circ} \mathrm{C}$ than at 20 and $30^{\circ} \mathrm{C}$. The shortest female survival time of $E$. scutalis was at $30^{\circ} \mathrm{C}$ as 10.1 , followed by 23.7 days and 28.6 days at 20 and $25^{\circ} \mathrm{C}$, respectively. Raze et al. (2005) revealed that temperature had significant influence on the biology of Euseius septicus Chaudhari. They concluded that the most favorable temperature for the continuity of the developmental processes of the predatory mite $E$. septicus fed on $T$. urticae was $25^{\circ} \mathrm{C}$.

Yue et al. (1994), noticed that Euseius mesembrinus (Dean) developed in 8-5-12.5 days after feeding on different kinds of pollen grains. The present results agree with those of El-Laithy and 
Fouly (1992), who noticed that male and female life cycle of $E$. scutalis averaged 6.8 and 7.8 days, respectively at $25^{\circ} \mathrm{C}$. Immature stages of $T$. urticae generaily accelerated the development of the predator more than those of Eutetranychus orientalis (Xlein), while immature stages of Oligonychus afrasiaticus (McGregor) were less preferred prey tope.

\section{REFERENCES}

Abd El-Halim, S. M.; Hanna M. A.; Abdella M. M. and Ramadan M. F. 2000. Evaluation of food type, availability of food and competition as factors affecting mass rearing of the predaceous mite Euseius scutalis (Athias-Henriot) (AcariPhytoseiidae). Egypt. J. Biol. Pest. Cont., $10(1 \& 2): 28-33$

Abou-Setta, M. M. and Childers, C. C. 1987. Eology of Euseius mesembrinus (Acari: Erytoseiidae): life tables on plant pollen c. different temperatures with notes on thiavior and food range. Exp. Appl. Acarol., $3(2): 123-130$.

-Shammery, K. A., 2010. Different biological aspects of the predaceous mite Euseius scutalis (ficari: Gamasida: Phytosiidae) and the effects due to feeding on three tetranychid mite species in Hail, Saudi Arabia. Asian J. Biol. Sci., 3:77-84.

Eounfour, M. and McMutry J. A. 1987. Biology and ecology of Euseius scutalis (Acarina: Phytoseiidae). Hilgardia, 55(5): 23pp.

Ei-Laithy, A. Y. M. and Fouly A. H. 1992.
Life table parameters of the two phytoseiid predtors Amblyseius scutalis (Athias- Henriot) and Amblyseius swirikii A. H. (Acari, Phytoseiidae) in Egypt. J. applied Entomol., 113. 8-12.

Furtado, I. P. and Moraes, G. J. D. 1998. Biology of Euseius citrifolius, a candidate for the biological control of Mononychellus tanajoa (Acari: Phytoseiidae, Tetranychidae). Sys. Appl. Acarol., $3: 43-48$.

Kasap, I. 2008. Influence of temperature on life table parameters of the predaceous mite, Euseius finlandicus (Oudemans) (Acari: Phytoseiidae). Turk. J. Agric. For., 32:1-8.

Kasap, I. and Sekeroglu E. 2004. Life history of Euseis scutalis feeding on citrus red mite Panonychus citri at various temperatures. Biocontrol, 49: 645-654.

McMurtry, J. A. and Croft B. A. 1997. Life-styles of phytoseiid mites and their roles in biological control. Annual Review Entomology, 42:291321.

Raza, A. B. M., Afzal M. and Bashir M. H. 2005. Biology of Euseius septicus Chaudhari (Acari: Phytoseiidae) preying on two spotted spider mite, Tetranychus urticae (Acari: Tetranychidae) at different temperatures. Eak. Entomol. $27,(1): 85-88$.

SAS institute 1988. SAS/Stat users guide, 6.03, ed. SAS Institute, Cary, NC.

Yue, B., Childers C. C. and Fouly A. H. 1994. A comparison of selected plant pollens for rearing Euseius membrinus (Acari: Phtosiidae). Int. J. Acarol., 20:103-108. 